Case Report

\title{
Granulomatous lesions in multiple organs in a horse caused by Halicephalobus gingivalis
}

\author{
Clarissa H. Santana, Letícia B. Oliveira, Samantha P. Pimentel, Barbara L. L. Mendes, Ana Paula R. \\ Silva, Renata P. A. Maranhão, Raffaella B. C. Teixeira, Roselene Ecco* \\ Departamento de Clínica e Cirurgia Veterinárias, Escola de Veterinária, Universidade Federal de Minas Gerais - UFMG, Brazil. \\ *Corresponding author: Departamento de Clínica e Cirurgia Veterinárias, Escola de Veterinária, UFMG, Belo Horizonte, MG, CEP 30123-970 Brasil. E- \\ mail: ecco@vet.ufmg.br
}

Submitted September, $1^{\text {st }} 2018$, Accepted October, $21^{\text {th }} 2018$

\begin{abstract}
The present report describes the clinical, macroscopic and histologic findings associated with Halicephalobus gingivalis infection in a male Arab horse, in the state of Minas Gerais, Brazil. The animal presented with acute neurologic signs that quickly progressed to a comatose status. Due to the lack of response to therapy, rapid progression of signs and poor prognosis, the horse was euthanized. Post-mortem examination revealed large granulomatous nodules in the kidneys. Renal and internal iliac lymph nodes were enlarged and with loss of corticomedullary distinction. Histopathology revealed granulomatous encephalitis, nephritis, lymphadenitis and focal granulomatous pneumonia associated with marked and chronic infection caused by $H$. gingivalis. This is the first report of $H$. gingivalis infection in horses in Minas Gerais. $H$. gingivalis infection should be included in the list of differential diagnosis of equine neurologic diseases in the state of Minas Gerais.
\end{abstract}

Key words: parasitic, encephalitis, nephritis, lymphadenitis, neurologic diseases.

\section{Introduction}

Halicephalobus gingivalis is a nematode, genus Halicephalobus, order Rhabditida, superfamily Rhabditoidea and family Rhabditidae. It has a smooth and thin cuticle, with transverse striations, conical tail ending in fine point, elongated buccal cavity and a rhabditiform esophagus. It was described for the first time by Stefansky in 1954, in a granuloma in the gingivae of a horse in Poland (2).

H. gingivalis is a free-living nematode, commonly encountered in the soil and organic matter. Its life cycle and pathogenesis are not completely understood. It is believed that it multiplies by parthenogenesis and mucosal and skin lesions are the major portal of entry (16). Other proposed routes of infection, based on naturally infected animals, are the reproductive tract, by uterine infection (10), prenatal, perinatal and transmammary (20). The parasite spreads to other organs probably by hematogenous or lymphatic routes. There are reports of possible dissemination to the optic and trigeminal nerve, and to the lacrimal duct $(4,11,15,16)$.

$H$. gingivalis infection is rare, but it has been documented in several countries, with most of the human and equine cases reported in Europe, North America and Northeast Asia (23). Most of the cases are reported in horses $(1,2,4,5,6,9,11,15,16,17,18,20,21,23)$, but it has also been described in a zebra, causing nephritis, myocarditis, uveitis, endometritis and granulomatous lymphadenitis (10), and calves with meningoencephalitis (7). There are human reports of meningoencephalitis caused by $H$. gingivalis, characterizing it as a potential zoonotic agent $(12,3)$.

The frequency of $H$. gingivalis infection in Brazil appears to be low, since there are just three documented cases in the country $(23,18,5)$. Skin and nervous system 
lesions are frequently reported in cases of $H$. gingivalis infection, with just a few reports of multiple organ involvement. This article describes the clinical and histopathologic findings in a horse with $H$. gingivalis infection in multiple organs and central nervous system.

\section{Case Report}

A 9-year-old, male, Arab horse, from the State of Minas Gerais, Brazil, was admitted at the veterinary teaching hospital, with a history of acute development of ataxia and depression. A day prior to admission the animal was first noted to be uncoordinated and reluctant to move. When moved out of the stall, he felt down hitting his head. Therapy with steroidal and non-steroidal antiinflammatory drugs was instituted by the referring veterinarian (unknown drugs and dosages); however, the animal had no improvement and it was then referred to the veterinary hospital. He was anesthetized at the horse training facility with detomidine and ketamine for the trailer ride. The horse belonged to a riding school, where no other animals presented neurological signs. The horses at the property were frequently dewormed with oral Ivermectin, but the exact dates and frequency were unknown. The horse from this report was vaccinated against rabies, tetanus, influenza and east/west encephalomyelitis. At admission, the horse was still anesthetized, in left lateral recumbency. Physical exam revealed hypothermia $\left(36,1^{\circ} \mathrm{C}\right)$, dry mucous membranes and increased capillary refill time. Skin ulcers secondary to decubitus were noted in the tuber coxae, head and limbs. A superficial wound, probably from the previous fall, was present in the atlanto-occipital region. Intravenous (IV) fluid therapy was initiated with a hypertonic saline solution at $7,2 \%$, followed by Ringer lactate solution. Therapy with dimethyl sulfoxide IV, ceftiofur and dexamethasone was also instituted. When no longer anesthetized, the horse made several unproductive attempts to stand. The neurological signs progressed in the first 24 hours to bilateral ventromedial strabismus, reduction of menace response, until it became unresponsive to the surroundings. A cerebrospinal fluid (CSF) tap was performed and revealed no change in color (clear), protein concentration $(34,02 \mathrm{mg} / \mathrm{dL})$ and glucose $(61,5 \mathrm{mg} / \mathrm{dL})$. A mild increase in nucleated cells was observed $(20$ cells $/ \mu \mathrm{L}$, reference value: 5 cells $/ \mu \mathrm{L}$ ). No erythrocytes, eosinophils or parasitic structures were observed. Skull radiograph showed no significant abnormalities. Due to the progression of the neurological signs and poor prognosis, the horse was euthanized.

At necropsy, multifocal lacerations were present on the skin of the forehead and limbs. In the kidneys, there were multifocal nodules, ranging from 2 to $15 \mathrm{~cm}$, elevated, white-yellowish in the center, red on the edges and firm. In the right kidney, the lesion replaced, approximately, fifty percent of the renal parenchyma (Fig. $1 \mathrm{~A}$ and $\mathrm{B})$. The renal and internal iliac lymph nodes were moderately enlarged, firm and with loss of corticomedullary distinction (Fig. 2). Meninges and parenchyma of the brain were moderately hyperemic. Representative tissue samples were fixed in $10 \%$ buffered formalin, processed, embedded in paraffin, sectioned at 5 $\mu \mathrm{m}$ and routinely stained with hematoxylin and eosin.

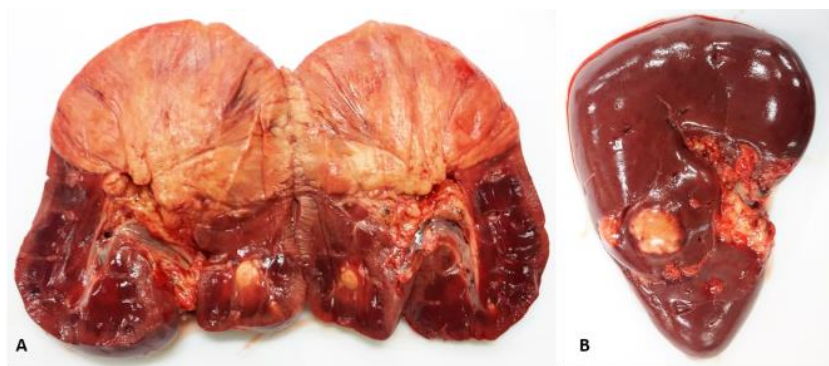

Figure 1. Kidney. Right (A) and left (B) kidney with partial replacement of the parenchyma by multifocal, welldefined, elevated, white and firm nodules, ranging from 2 to $15 \mathrm{~cm}$.

Figure 2. Internal iliac lymph node. The parenchyma is moderately enlarged and bulged on cut surface. There is loss of corticomedullary distinction and replacement by yellow and white millimetric areas.

Histopathology revealed significant lesions in the brain, kidneys, renal/ internal iliac lymph nodes and lungs. In the frontal and parietal cortex, brainstem, cerebellum and neurohypophysis (Fig. 3) there was a marked inflammatory infiltration. These cells were characterized by lymphoplasmacytic and histiocytic infiltration, with epithelioid macrophages and multinucleated giant cells, with numerous parasites, characterizing a multifocal granulomatous and parasitic encephalitis. The parasite structures were elongated, with 80 to $90 \mu \mathrm{m}$ long, with cylindrical and sharp ends, covered by smooth cuticle, platimiarian musculature and an evident elongated and central rhabditiform esophagus, occupying the initial third 
of the body and intestine. This morphology is consistent with $H$. gingivalis. In some nematodes it was possible to see eggs in the reproductive system. Around the parasites there were areas of linear malacia, with many gitter cells and axonal spheroids, delimitating regions of possible larvae migration (Fig. 4A and B). There was also vasculitis and moderate number of neurons in chromatolysis.

The kidneys had partial loss of the parenchyma, replaced by granulomatous inflammatory infiltrate, similar to the lesions described in the brain, with abundant $H$. gingivalis specimens, characterizing marked granulomatous nephritis (Fig. 5A). There was also interstitial fibroplasia, necrosis and vasculitis. The remaining renal tubules were dilated and filled by macrophages, neutrophils, cellular debris and numerous longitudinal and transverse sections of $H$. gingivalis (Fig. $5 B)$.

The renal and internal iliac lymph nodes' parenchyma was replaced by severe granulomatous inflammatory infiltration similar to the findings in the brain and kidneys, with an abundant amount of $H$. gingivalis specimens (Fig. 6). There were blood and lymphatic vessels filled with $H$. gingivalis, vasculitis and moderate lymphoid hyperplasia. The histopathology of the lung revealed a focal granulomatous inflammatory infiltrate with the same parasitic structures found in the organs described above (Fig. 7).

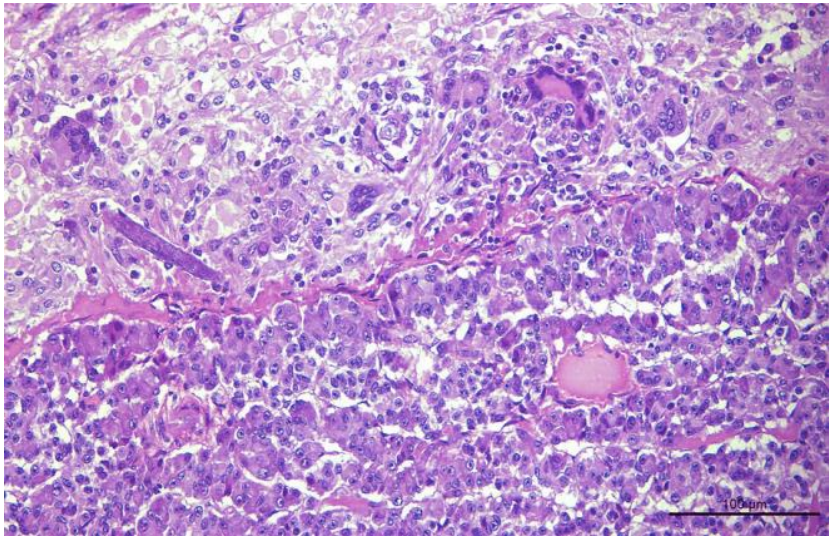

Figure 3. Hypophysis. Neurohypophysis with granulomatous inflammatory infiltration associated with parasitic structures morphologically similar to $H$. gingivalis and axonal spheroids. Hematoxylin and eosin, bar $=100 \mu \mathrm{m}$.

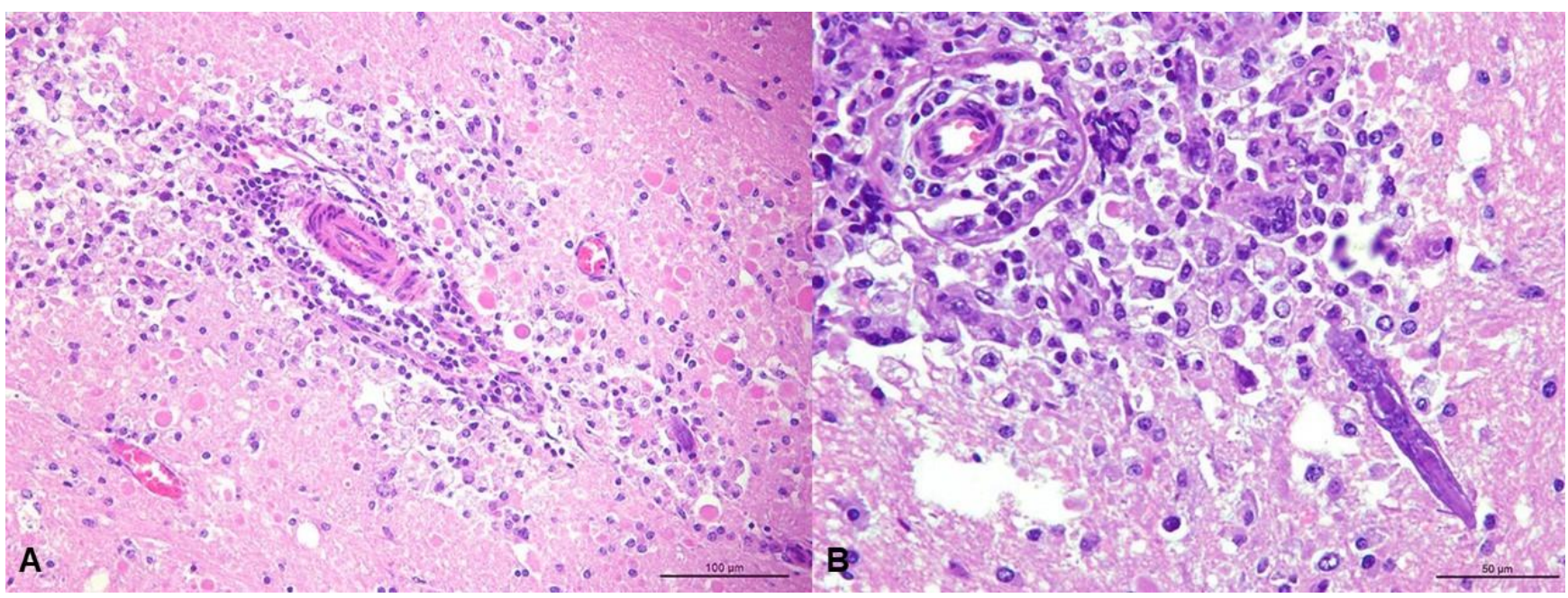

Figure 4. Brain. Frontal A. and parietal B. cortex with granulomatous inflammatory infiltration associated with parasitic structures, with morphology similar to $H$. gingivalis, many gitter cells, malacia, edema and axonal spheroids. B. Longitudinal section of parasite with approximately, $80 \mu \mathrm{m}$ long, cylindrical, with sharp ends, covered by smooth cuticle, platimiarian musculature and an evident elongated and central rhabditiform esophagus, morphologically similar to $H$. gingivalis. Hematoxylin and eosin, bar $=100$ A. e $50 \mu \mathrm{m} \mathrm{B.}$

\section{Discussion}

Post-mortem examination revealed encephalitis, nephritis, lymphadenitis and granulomatous pneumonia associated with chronic and severe Halicephalobus gingivalis infection. There are just three reports of $H$. gingivalis infection in horses in Brazil, in the state of São Paulo (23), Goiás (18) and Rio de Janeiro (5). Two of those presented only meningoencephalitis $(18,23)$, and one had granulomatous myocarditis (5). The microscopic lesions and parasite morphology found in the present study are similar to previous reports, but the lesion distribution varied since the horse described here had meningoencephalitis associated with lesions in the kidneys, lymph nodes and lungs. Previous reports described lesions in the CNS, kidney, myocardium, retina, bone, lymph nodes, skin, lung and testicle $(5,6,9,10,11$, $16,17,23,18,21)$. This is the first report of $H$. gingivalis infection in the state of Minas Gerais. 


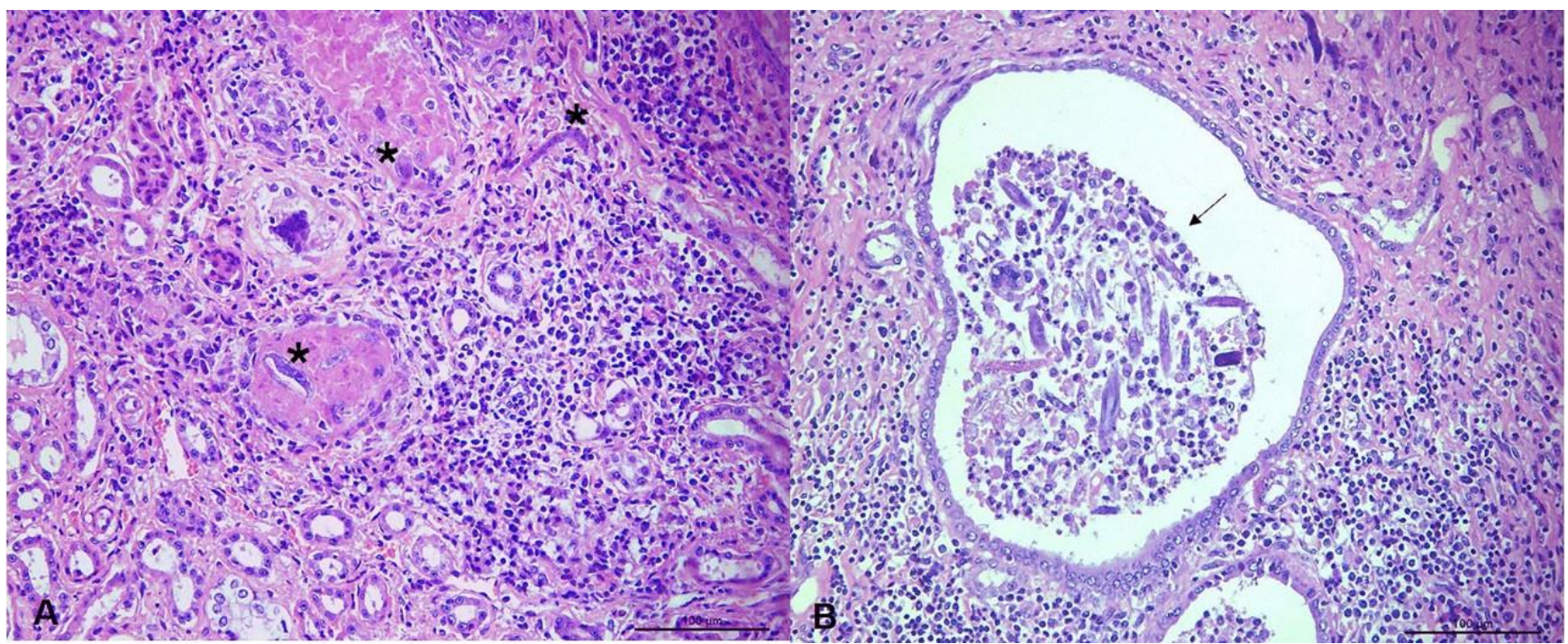

Figure 5. Kidney. A. Interstitial with granulomatous inflammatory infiltrate associated with parasites morphologically similar to $H$. gingivalis $(*)$. B. Renal tubules dilated and filled by inflammatory cells and many longitudinal and transverse sections of $H$. gingivalis (arrow). Hematoxylin and eosin, bar $=100 \mu \mathrm{m}$.

The detailed deworming history of the horse from the present report, and the other horses at the same farm was unknown. There are reports of $H$. gingivalis infection in horses after Ivermectin administration, suggesting that either this drug or the recommended dose to treat gastrointestinal parasites are not effective against $H$. gingivalis, or that the infection occurred after the drug effect was over $(4,15,18)$. There are just two reports where Ivermectin was effective in treating $H$. gingivalis infection in horses; in both cases only the skin was affected and in one of them the treatment was associated with surgical excision of the lesion $(6,15)$. So far, an effective treatment protocol has not been described. It is possible that the rapid progression of the disease, associated with the large size of the granulomatous lesions caused by the parasites, prevent appropriate drug penetration. This is even more challenging in cases of parasitic meningoencephalitis, since the capability of antihelminthic drugs to penetrate the CNS is unknown (8).

Clinical signs of $H$. gingivalis infection reflect the distribution and severity of the lesions in the central nervous system (CNS) and can vary from depression (21) to more severe neurologic signs such as ataxia, nystagmus and peddling movements (18).

Spinal fluid (CSF) analysis collected post-mortem from a horse with $H$. gingivalis meningoencephalitis revealed increased protein concentration $(0,89 \mathrm{~g} / \mathrm{L})$, glucose and cell count $(2,03 \times 103$ cells/ $\mu \mathrm{L})(4) . H$. gingivalis has been previously detected in the spinal fluid of a neurologic horse, confirmed later with histopathology and polymerase chain reaction (PCR) (1). Although these findings demonstrate the importance of CSF analysis, there are no reports showing the correlation between changes in the CSF with the duration and severity of the lesions in the CNS. The horse from the present report had high concentration of parasites and severe inflammatory reaction in the CNS histopathology, but apart from a mild increased in spinal fluid cellularity, no other changes were noted, confirming that parasite migration should not be ruled out based on a normal CSF analysis (8).

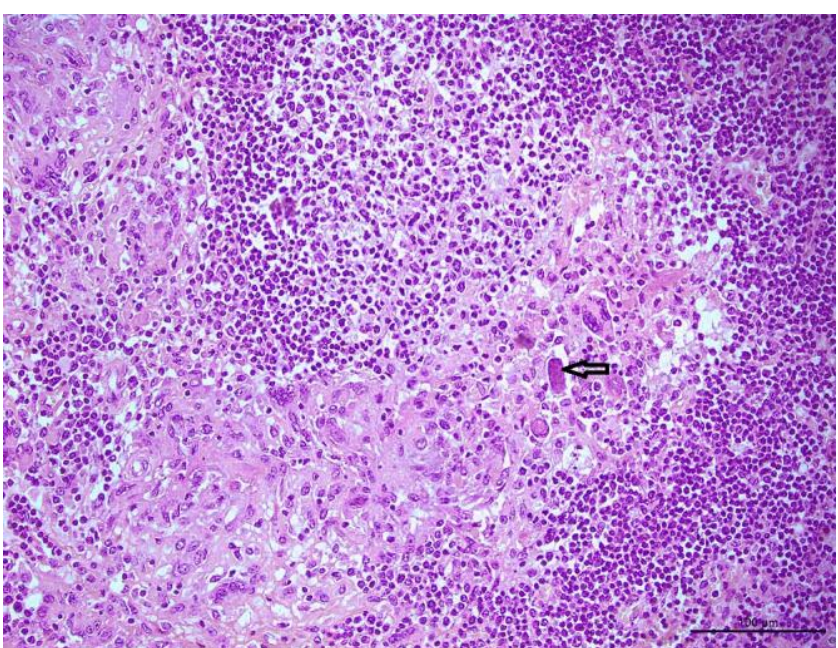

Figure 6. Lymph nodes. Parenchyma with granulomatous inflammatory infiltrate associated with parasites morphologically similar to $H$. gingivalis (arrow). Hematoxylin and eosin, $\mathrm{bar}=100 \mu \mathrm{m}$.

The gross and microscopic lesions reported in the kidneys are similar to previous reports $(9,10,11,14,21)$. The nodular and solid appearance of the kidney resembled neoplasia. Similar lesions were described in a zebra with renal lesions caused by $H$. gingivalis (10). Similar to previous reports, numerous nematodes (entire and fragmented) were seen in the renal tubular lumen $(11,21)$. The parasite has also been found in a urine sample of a horse, collected post-mortem $(11,21)$. These findings suggest that nematode excretion in the urine can be a cause 
of environmental contamination and consequent human and animal infection through penetration of the parasite in skin or mucosal lesions. Those findings also suggest that evaluation of urine samples in horses with suspected $H$. gingivalis infection can support an ante-mortem diagnosis of the disease. Evaluation of the semen, when there is involvement of the testicles, could also aid in the antemortem diagnosis of the disease (11).

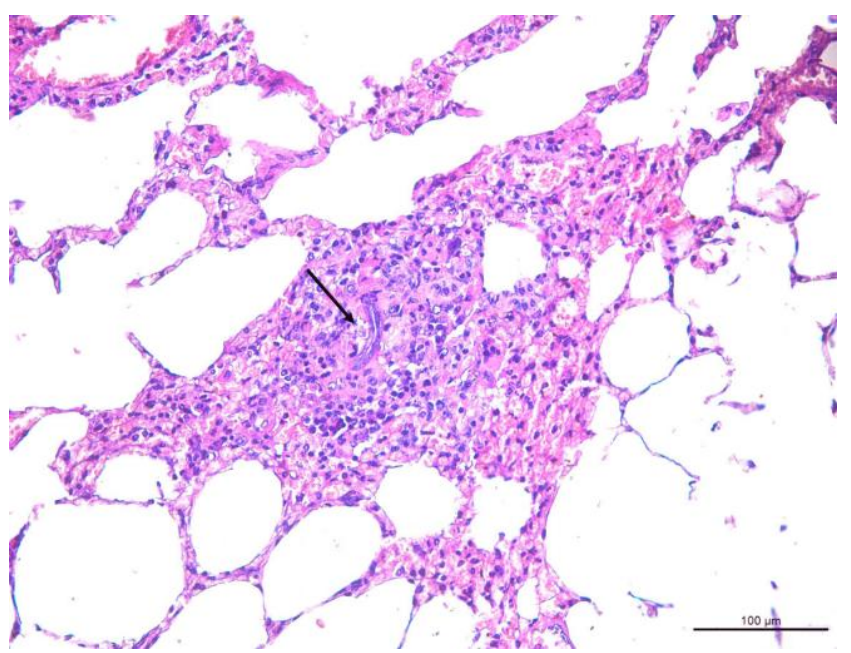

Figure 7. Lung. Parenchyma with focal granulomatous inflammatory infiltrate associated with parasite morphologically similar to $H$. gingivalis (arrow). Hematoxylin and eosin, bar $=50 \mu \mathrm{m}$.

Granulomatous lymphadenitis, similar to findings previously reported in a zebra, were observed in the renal lymph nodes of the horse from this report, suggesting that lymphatic migration of the parasites occurs and should be considered a possible route of dissemination (10). Consistent with previous reports $(4,18,21)$, parasites were also found in the lumen of blood vessels and free in the space of Virchow-Robins in the brain, suggesting that hematogenous spread of the parasite should also be considered.

Little is known about the epidemiology of $H$. gingivalis infection. Commonly, as observed in the present report, infected horses live with other animals that do not develop clinical signs $(6,10,18)$. Prognosis is poor, especially when there is CNS involvement.

In reported human cases of meningoencephalitis caused by $H$. gingivalis, the diagnoses were made on postmortem examination $(3,13,19)$. Only in one of them, human contact with horses and infection was reported, supporting the zoonotic character of this parasite (3). In most cases no obvious source of infection was identified $(19,13)$. Humans with $H$. gingivalis infection, in contrast to horses, show little to no neurological signs (13).

The present report shows that $H$. gingivalis can cause marked lesions that lead to morphological and functional changes in the tissue of several organs. $\mathrm{H}$. gingivalis is present in the state of Minas Gerais and should be considered in the differential diagnosis in horses with neurological signs and granulomatous infections.

\section{References}

1. Adedeji AO, Borjesson DL, Kozikowski-Nicholas TA, Cartoceti AN, Prutton J, Aleman M. What is your diagnosis? Cerebrospinal fluid from a horse. Vet Clin Pathol. 2015;44(1):171-2.

2. Anderson RC, Under KE, Peregrine AS. Halicephalobus gingivalis (Stefanski, 1954) from a fatal infection in a horse in Ontario, Canada with comments on the validity of $H$. deletrix and a review of the genus. Parasite.1998;5:255-61.

3. Anwar MA, Gokozan HN, Ball MK, Otero J, McGwire BS. Fatal human eosinophilic meningoencephalitis caused by CNS co-infection with Halicephalobus gingivalis and West Nile virus. Parasitol Int. 2015;64:417-20.

4. Brojer JT, Parsons DA, Linder KE, Peregrine AS, Dobson H. Halicephalobus gingivalis encephalomyelitis in a horse. Can Vet J. 2000;41:55961.

5. Cunha BM, França TN, Miranda IC, Santos AM, Seixas JN, Pires APC, Santos BBN, Peixoto PV. Miocardite granulomatosa em cavalo por Halicephalobus gingivalis $(H$. deletrix) - Relato de caso. Rev Braz Med Vet. 2016;38(2):113-6.

6. Dunn DG, Gardiner CH, Dralle KR, Thilsted JP. Nodular Granulomatous posthitis caused by Halicephalobus (syn. Micronema) sp. in a horse. Vet Pathol. 1993;30:207-8.

7. Enemark HL, Hansen MS, Jensen TK, Larsen G, AlSabi MNS. An outbreak of bovine meningoencephalomyelitis with identification of Halicephalobus gingivalis. Vet Parasitol. 2016;218:82-6.

8. Furr M. Parasitic Infections of the Central Nervous System. In: Furr M, Reed S, editors. Equine Neurology. 2nd ed. Ames, Iowa: John Wiley \& Sons; 2015. p. 306-13.

9. Henneke C, Jespersen A, Jacobsen S, Nielsen MK, McEvoy F, Jensen HE. The distribution pattern of Halicephalobus gingivalis in a horse is suggestive of a haematogenous spread of the nematode. Acta Vet Scand. 2014;56:1-4.

10. Isaza R, Schiller CA, Stover J, Smith PJ, Greiner EC. Halicephalobus gingivalis (nematoda) infection in a grevy's zebra (Equus grevyi). J Zoo Wild Med. 2000;31(1):77-81.

11. Kinde H, Mathews M, Ash L, Leger JSt. Halicephalobus Gingivalis (H. Deletrix) infection in two horses in southern California. J Vet Diagn Invest. 2000;12(2):162-5.

12. Lim CK, Crawford A, Moore CV, Gasser RB, Nelson R, Koehler AV, Bradbury RS, Speare R, Dhatrak D, Weldhagen GF. First human case of fatal 
Halicephalobus gingivalis meningoencephalitis in Australia. J Clin Microbiol. 2015;53:1768-74.

13. Monoranu CM, Müllges W, Keppler M, Brehm K, Ondrejka SL, Muntau B, Tannich E, MüllerHermelink HK, Tappe D. Fatal human meningoencephalitis due to Halicephalobus nematodes, Germany. Open Forum Infect Dis. 2015;2(2):1-3.

14. Noiva R, Ruivo P, de Carvalho LM, Fonseca C, Fevereiro M, Carvalho P, Orge L, Monteiro M, Peleteiro MC. First description of a fatal equine infection with Halicephalobus gingivalis in Portugal. Relevance for public health. Vet Med Sci. 2019;5(2):1-8.

15. Pearce SG, Bouré LP, Taylor JA, Peregrine AS. Treatment of a granuloma caused by Halicephalobus gingivalis in a horse. J Am Vet Med Assoc. 2001;219(12):1735-8.

16. Rames DS, Miller DK, Barthel R, Craig TM, Dziezyc J, Helman RG, Meale R. Ocular Halicephalobus (syn. Micronema) deletrix in a horse. Vet Pathol. 1995;32(5):540-2.

17. Roullet A, Semin MO, Raymond IL, Cuevas GR. Massive mandible osteolysis caused by Halicephalobus gingivalis in a mare. Vet Rec Case Rep. 2014;2:1-5.

18. Sant'Ana FJF, Júnior JAF, Costa YL, Resende RM, Barros CSL. Granulomatous meningoencephalitis due to Halicephalobus gingivalis in a horse. Braz $\mathbf{J}$ Vet Pathol. 2012;5(1):12-5.

19. Shadduck JA, Ubelaker J, Telford VQ. Micronema deletrix meningoencephalitis in an adult man. Am J Clin Pathol. 1979;72(4):640-3.

20. Spalding MG, Greiner EC, Green SL. Halicephalobus (Micronema) deletrix infection in two half-sibling foals. J Am Vet Med Assoc. 1990;196(7):1127-9.

21. Taulescu MA, Ionicã AM, Diugan E, Pavaloiu A, Cora R, Amorim I, Catoi C, Roccabianca P. First report of fatal systemic Halicephalobus gingivalis infection in two Lipizzaner horses from Romania: clinical, pathological, and molecular characterization. Parasitol Res. 2015;115(3):1907-2103.

22. ThankGod EO, Theresa OO, Oluwasina SO, Dennis OO, Abdullahi AB, Albert WM. Parasitic and zoonotic meningoencephalitis in humans and equids: Current knowledge and the role of Halicephalobus gingivalis. Parasite Epidemiol Control. 2018;3(1):3642.

23. Vasconcelos RO, Lemos KR, Moraes JRE, Borges VP. Halicephalobus gingivalis $(H$. deletrix) in the brain of a horse. Cienc Rural. 2007;37(4):1185-7. 